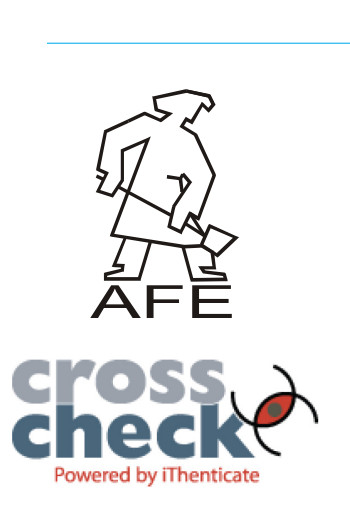

\title{
Structure and Usable Properties of Aluminum Continuous Ingots
}

\author{
T. Wróbel *, J. Szajnar, D. Bartocha, M. Stawarz \\ ${ }^{a}$ Silesian University of Technology, Foundry Department, Towarowa 7, 44-100 Gliwice, PL \\ *Corresponding author. E-mail address: tomasz.wrobel@polsl.pl
}

Received 20.05.2015; accepted in revised form 29.05.2015

\begin{abstract}
In paper is presented results of studies concerning ingot of $\mathrm{Al}$ with a purity of $99.5 \%$ cast with use of stand of horizontal continuous casting. Mainly together with casting velocity was considered influence of electromagnetic stirrer, which was placed in continuous casting mould on refinement of ingots structure and theirs usability to plastic deformation. Effect of structure refinement and usability to plastic deformation obtained by influence of electromagnetic stirring was compared with refinement obtained by use of traditional inoculation, which consists in introducing of additives i.e. Ti and B to metal bath. On the basis of obtained results was affirmed that inoculation realized by electromagnetic stirring in range of continuous casting mould guarantees improvement in structure refinement and usability to rolling of pure $\mathrm{Al}$ continuous ingots.
\end{abstract}

Keywords: Continuous casting, Aluminum, Structure, Inoculation, Electromagnetic stirring

\section{Introduction}

The technology of continuous casting is applying usually in production of ingots of $\mathrm{Fe}[1 \div 4], \mathrm{Al}[5 \div 8]$ or $\mathrm{Cu}[9,10]$ alloys, with high yield and quality. The quality of continuous ingot in comparison with traditional gravity casting with use of ingot permanent mould concerns refinement and uniform of ingot structure, which results from solidification of metal in water cooled continuous casting mould.

Moreover the refinement of ingot structure can be increases by forced liquid metal movement in time of its solidification results from influence of electromagnetic stirring $[1 \div 14]$. The forced liquid metal movement guarantees limitation of unfavorable (mainly for plastic deformation of ingot) columnar macrograins from ingot primary structure at simultaneously increase amount of favorable equiaxed macrograins.

Other method of structure refinement is use of traditional inoculation consists in introducing into metal bath of specified substances, called inoculants. Inoculants increase grains density as result of creation of new particles in consequence of braking of grains growth velocity, decrease of surface tension on interphase boundary of liquid - nucleus, decrease of angle of contact between the nucleus and the base and increase of density of bases to heterogeneous nucleation. The effectiveness of this type of inoculation depends significantly on crystallographic match between the base and the nucleus of inoculated metal. Therefore active bases to heterogeneous nucleation for aluminum are particles, which have high melting point i.e. titanium borides, titanium carbides, titanium nitrides, aluminum borides and aluminum titanide $[11 \div 14]$. But this effective method of inoculation in comparison with inoculation with use of electromagnetic field has three faults i.e. inoculants decrease the degree of purity and electrical conductivity of pure aluminum [11] and moreover are reason of point cracks formation during rolling of ingots [15].

Therefore the aim of studies was determined the influence of inoculation with use of electromagnetic field at defined casting velocity on structure refinement and usability to plastic deformation of continuous ingot $\$ 30 \mathrm{~mm}$ of $\mathrm{Al}$ with a purity of 
$99,5 \%$. Effect of structure refinement and usability to plastic deformation obtained by influence of electromagnetic stirring was compared with refinement obtained by use of traditional inoculation, which consists in introducing of additives i.e. Ti and B to metal bath.

\section{Range of studies}

On Fig. 1 view of the stand of horizontal continuous casting, which was constructed in Foundry Department of Silesian University of Technology is presented. The main parts of the made stand belong to induction furnace, which is also tundish with a capacity of up to $60 \mathrm{~kg}$ of charge, water cooled continuous casting mould at flow rate from 0.1 to $101 / \mathrm{min}$, system of recooling, system of continuous ingot drawing and cutting, which realized method of ingot movement defined by combination of motion to forwards, stop and/or backwards performed in specified time and velocity from 100 to $500 \mathrm{~mm} / \mathrm{min}$ set in control system.

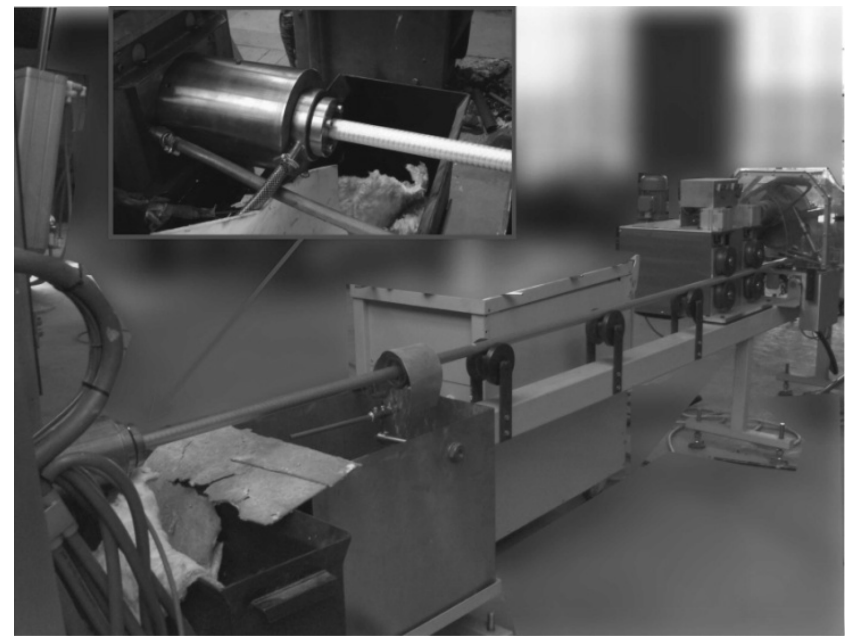

Fig. 1. View of stand of horizontal continuous casting

In presented studies was applied method of ingot movement defined by combination of motion to forwards in time of $1 \mathrm{~s}$ at velocity from 100 to $240 \mathrm{~mm} / \mathrm{min}$ and stop in time of $2 \mathrm{~s}$. In result of presented method of ingot movement in combination forwards/stop/forwards/stop/etc. was obtained average velocity from 30 to $80 \mathrm{~mm} / \mathrm{min}$. In dependence of used velocities the temperature of cooling water in continuous casting mould was set on $45 \div 55^{\circ} \mathrm{C}$ and temperature of ingot after leaving the continuous casting mould was equaled $150 \div 300^{\circ} \mathrm{C}$.

While in aim of realization of inoculation with use of electromagnetic field (IEF) was used electromagnetic stirrer placed in continuous casting mould (Fig. 2). In studies was applied rotating electromagnetic field with induction $60 \mathrm{mT}$ generated by stirrer supplied with current $8 \mathrm{~A}$ at frequency $100 \mathrm{~Hz}$.

Moreover was used traditional inoculation, which consists in introducing of additives i.e. Ti and $\mathrm{B}$ to metal bath in form of master alloy AlTi5B1 in amount 25 ppm Ti and 5 ppm B (IA).

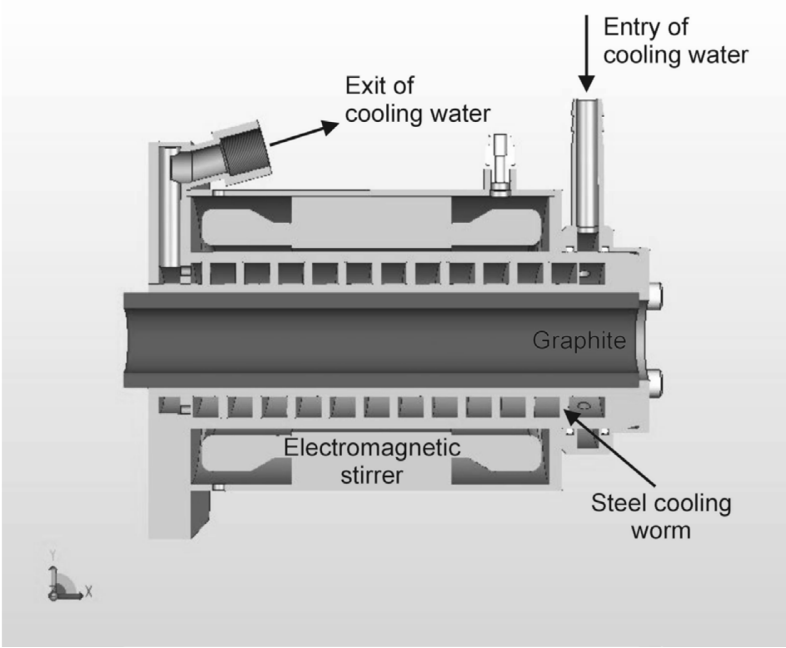

Fig. 2. View of water cooled continuous casting mould contains electromagnetic stirrer

The degree of primary structure refinement of $\mathrm{Al}$ continuous ingots was represented by equiaxed crystals zone content (SKR) on transverse section, average area of macro-grain in this zone (PKR) and average area of macro-grain in columnar crystals zone (PKK). Moreover was applied refinement coefficient (R) representing simultaneous three parameters i.e. PKR, PKK and $\mathrm{L}_{\mathrm{SKK}}$ (width of columnar crystals zone). Coefficient $\mathrm{R}$ is represented by area of scalene triangle (Fig. 3). According to this criterion area of triangle tending to a minimum corresponds to the increase of degree of refinement. In aim of realization of refinement measurements in pure $\mathrm{Al}$ structure macroscopic metallographic studies on transverse section of continuous ingots were carried out. Analyzed surface for macroscopic analysis was etched with use of solution of: $50 \mathrm{~g} \mathrm{Cu}, 400 \mathrm{ml} \mathrm{HCl}, 300 \mathrm{ml}$ $\mathrm{HNO}_{3}$ and $300 \mathrm{ml} \mathrm{H} \mathrm{H}_{2}$.

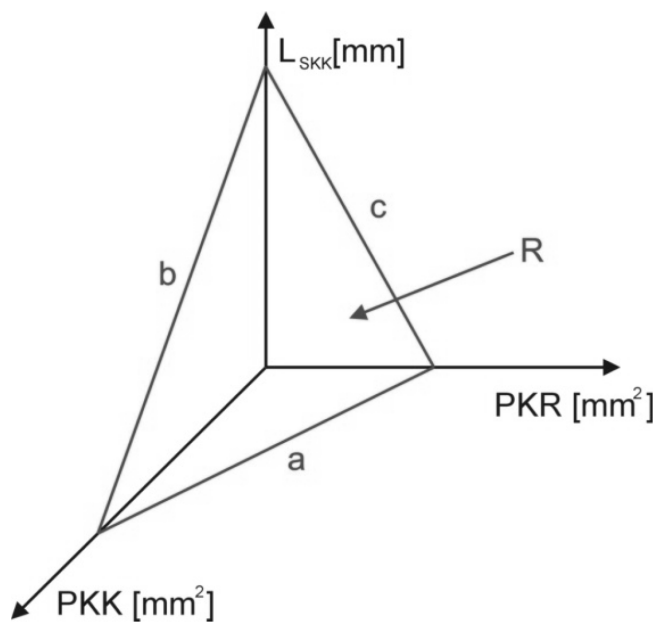

Fig. 3. Graphic interpretation of refinement coefficient $\mathrm{R}$ 
Usability to plastic deformation of $\mathrm{Al}$ with a purity of $99.5 \%$ cast in horizontal continuous casting process was determined on the basis of results of cold rolling of $\phi 30 \mathrm{~mm}$ ingots to $5 \mathrm{~mm}$ thick flats in 6 roll pass with intermediate annealing recrystallizing in $330^{\circ} \mathrm{C}$ by $1 \mathrm{~h}$. In these studies was used reversing rolling mill with rolls diameter $550 \mathrm{~mm}$ (Fig. 4).

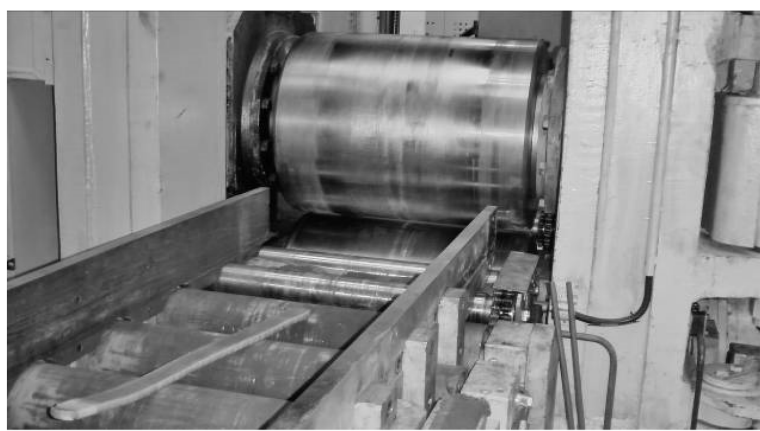

Fig. 4. View of cold rolling process of $\phi 30 \mathrm{~mm} \mathrm{Al}$ continuous ingot to $5 \mathrm{~mm}$ thick flat

\section{Results of studies}

In table 1 are presented macrostructures of $\mathrm{Al}$ with a purity of $99.5 \%$ continuous ingots respectively in initial state, after inoculation with use of electromagnetic stirring and after traditional inoculation with use of Ti and $\mathrm{B}$ additives. Whereas on Fig. $4 \div 7$ are presented results of measurements of parameters of primary structure refinement.

On the basis of obtained results was affirmed that in result of use of inoculation by electromagnetic stirring was obtained in horizontal continuous casting process refinement of primary structure of pure $\mathrm{Al}$. Compared to initial state is present decreasing of area of particular columnar and equiaxed macro-grains, however without increase in percentage content of equiaxed crystals zone on transverse section of continuous ingot. Increase in percentage content of equiaxed crystals zone on transverse section of $\mathrm{Al}$ continuous ingot with simultaneous decreasing of area of macro-grains in this zone was obtained in result of use of inoculation by small amount of Ti and B.

Moreover was affirmed that in case of $\mathrm{Al}$ in initial state and after inoculation by $\mathrm{Ti}$ and $\mathrm{B}$ is present negative influence on primary structure of increase of average velocity of ingot movement. In these cases simultaneous decreases percentage content of equiaxed crystals zone on transverse section and increases average area of equiaxed and columnar macro-grain. While in case of inoculation by electromagnetic stirring with increased in average velocity of ingot movement decreases average area of equiaxed and columnar macrograin, but similarly to the previous cases, occurred negative orientation of primary structure of ingot i.e. decrease of equiaxed crystals zone.

Summing on the bases of analysis concerning refinement coefficient $\mathrm{R}$ was affirmed generally negative influence of increase average velocity of ingot movement on primary structure of pure $\mathrm{Al}$ continuous ingot. However sensitivity of structure on changes in velocity of ingot movement can be reduced using inoculation by electromagnetic stirring or mainly by addition of Ti and B.

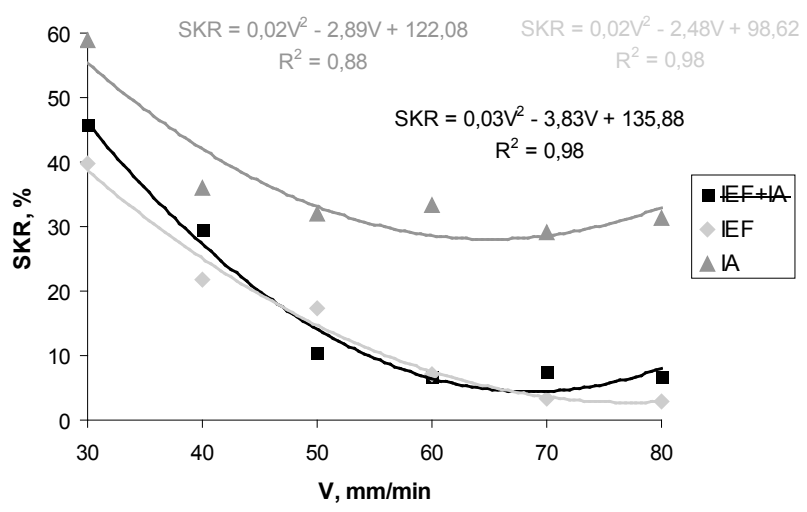

Fig. 5. Influence of average velocity of ingot movement (V) on percentage content of equiaxed crystals zone on transverse section (SKR) of $\mathrm{Al}$ continuous ingot in different state of inoculation (as marked in Tab. 1)

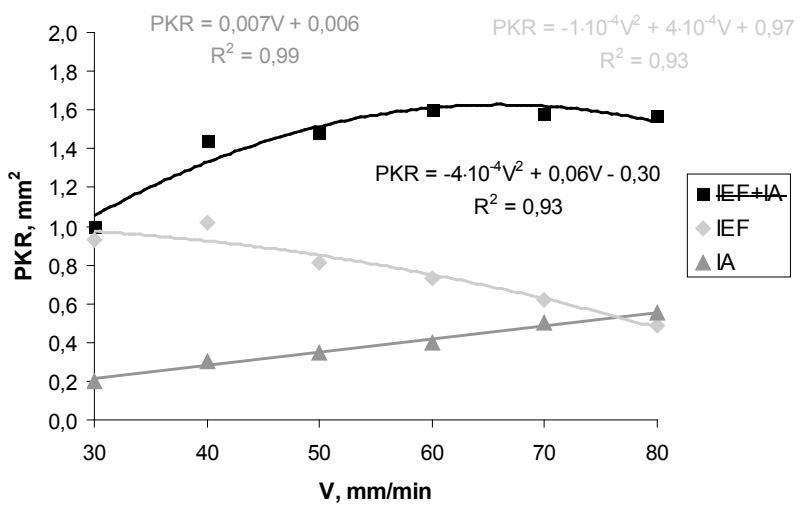

Fig. 6. Influence of average velocity of ingot movement (V) on average area of macro-grain in equiaxed crystals zone (PKR) of $\mathrm{Al}$ continuous ingot in different state of inoculation (as marked in Tab.1)

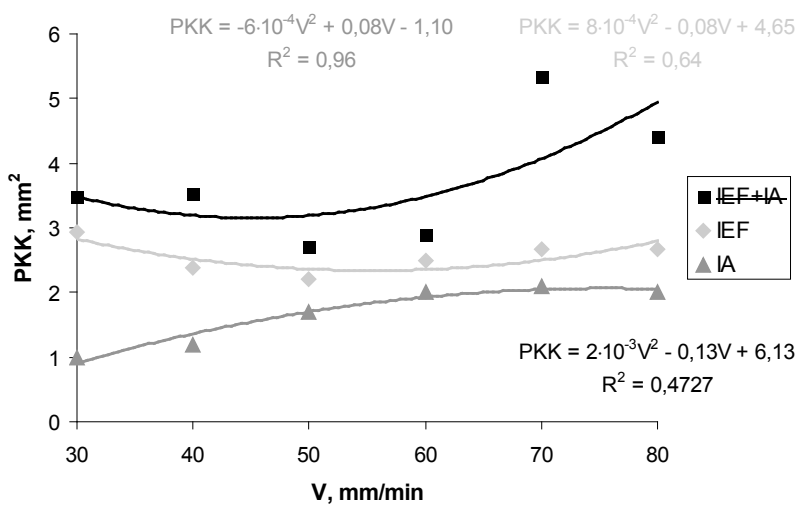

Fig. 7. Influence of average velocity of ingot movement (V) on average area of macro-grain in columnar crystals zone (PKK) of $\mathrm{Al}$ continuous ingot in different state of inoculation (as marked in Tab. 1) 
Table 1

Macrostructures of continuous ingots of $\mathrm{Al}$ with a purity of $99.5 \%$

\begin{tabular}{|c|c|c|c|}
\hline $\begin{array}{l}\text { Average velocity of ingot } \\
\text { movement } \mathrm{V}, \mathrm{mm} / \mathrm{min}\end{array}$ & $\begin{array}{l}\text { In initial state without } \\
\text { inoculation }(\text { IEF }+\mathrm{IA})\end{array}$ & $\begin{array}{l}\text { After inoculation with use of } \\
\text { electromagnetic stirring (IEF) }\end{array}$ & $\begin{array}{l}\text { After inoculation with use of } \\
\text { Ti and B additives (IA) }\end{array}$ \\
\hline \multicolumn{4}{|l|}{30} \\
\hline 40 & $10 \mathrm{~mm}$ & & \\
\hline \multicolumn{4}{|l|}{50} \\
\hline \multicolumn{4}{|l|}{60} \\
\hline \multicolumn{4}{|l|}{70} \\
\hline \multicolumn{4}{|l|}{80} \\
\hline & & & \\
\hline
\end{tabular}




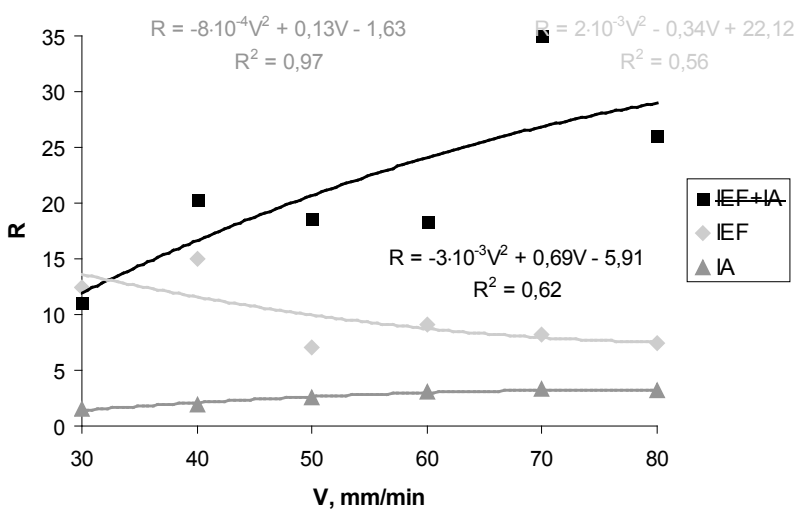

Fig. 8. Influence of average velocity of ingot movement (V) on refinement coefficient $(\mathrm{R})$ of $\mathrm{Al}$ continuous ingot in different state of inoculation (as marked in Tab.1)

On the basis of results of studies concerning evaluation of $\mathrm{Al}$ continuous ingots to rolling was affirmed that highest quality have flats obtained from ingots cast with inoculation by electromagnetic stirring. These flats is characterized by smooth surfaces free from any cracking (Fig. 8). Additionally for these flats was not affirmed influence of average velocity of ingot movement on their quality. While worse quality have flats obtained from ingots in initial state. On flats edges are present small delamination which can propagate into material (Fig. 9). The greatest concentration of this type of surface defects was found in ingot cast with average velocity $80 \mathrm{~mm} / \mathrm{min}$. The worst quality are characterized flats from ingots cast with inoculation by addition of $\mathrm{Ti}$ and $\mathrm{B}$. There are present cracks progressing from the edge into the flat (Fig. 10). Moreover for these flats was not affirmed influence of average velocity of ingot movement on their quality which is unsatisfactory.

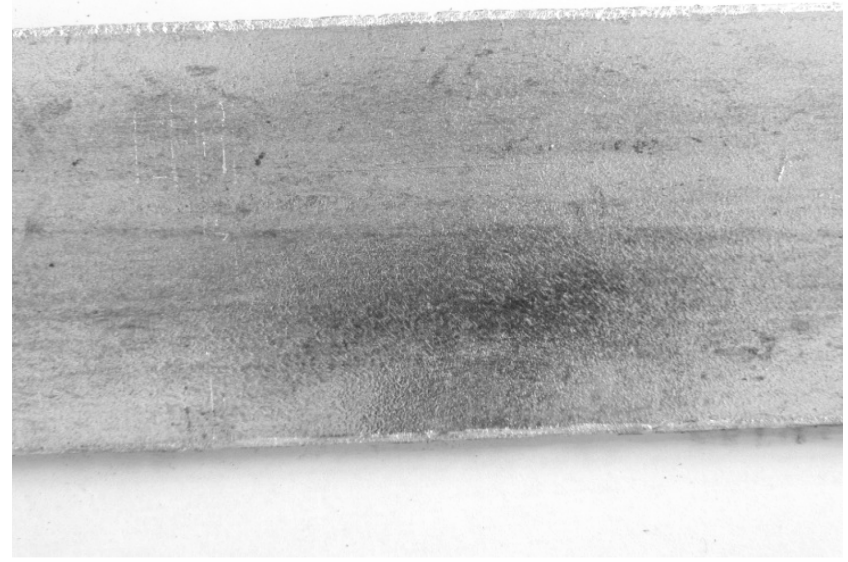

Fig. 9. Example view of part of flat thick $5 \mathrm{~mm}$ made by cold rolling from $\phi 30 \mathrm{~mm} \mathrm{Al} \mathrm{continuous} \mathrm{ingot} \mathrm{inoculated}$ by electromagnetic stirring

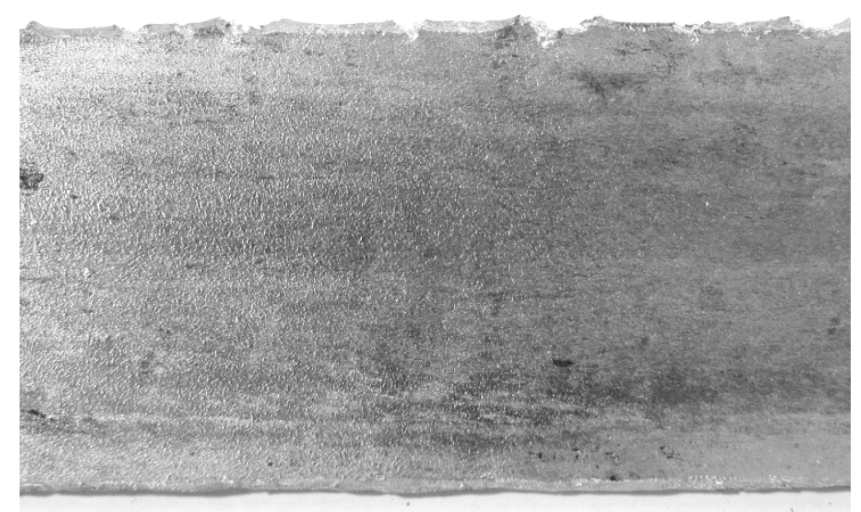

Fig. 10. Example view of part of flat thick $5 \mathrm{~mm}$ made by cold rolling from $\phi 30 \mathrm{~mm} \mathrm{Al}$ continuous ingot in initial state

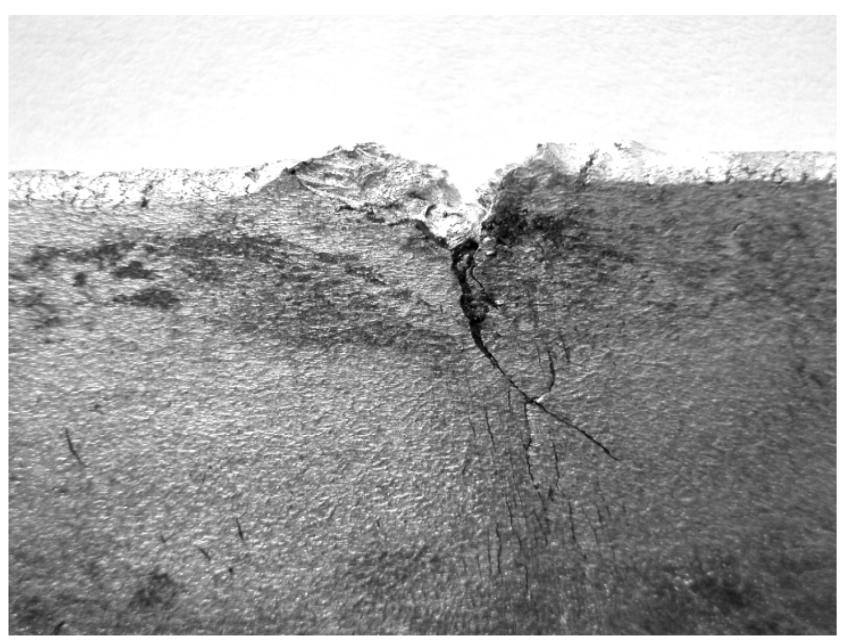

Fig. 11. Example view of part of flat thick $5 \mathrm{~mm}$ made by cold rolling from $\phi 30 \mathrm{~mm} \mathrm{Al}$ continuous ingot inoculated by additions of Ti and $\mathrm{B}$

\section{Conclusions}

Based on conducted studies following conclusions have been formulated:

1. Inoculation realized by electromagnetic stirring in range of continuous casting mould guarantees improvement in structure refinement and usability to rolling of pure $\mathrm{Al}$ continuous ingots.

2. Pure $\mathrm{Al}$ continuous ingots inoculated by electromagnetic stirring are characterized by larger refinement in comparison with initial state but simultaneous smaller in comparison to ingots inoculated by additions of $\mathrm{Ti}$ and $\mathrm{B}$. 
3. Pure Al continuous ingots inoculated by electromagnetic stirring have larger usability to plastic deformation than ingots in initial state or inoculated by additions of $\mathrm{Ti}$ and $\mathrm{B}$.

4. Increasing in average velocity of ingot movement negative influences on primary structure of pure $\mathrm{Al}$ continuous ingot. However sensitivity of structure on changes in velocity of ingot movement can be reduced using inoculation by electromagnetic stirring or mainly by addition of Ti and B.

\section{Acknowledgements}

Project financed from means of Polish National Science Centre.

\section{References}

[1] Adamczyk, J. (2004). Engineering of metallic materials. Gliwice: Publishers of Silesian University of Technology. (in Polish).

[2] Zhou, S., Li, H., Rao, J., Ren, Z., Hang, J. \& Yang, Z. (2007). Effect of electromagnetic stirring on solidification structure of austenitic stainless steel in horizontal continuous casting. China Foundry. 4(3), 198-201.

[3] Szajnar, J., Stawarz, M., Wróbel, T., Sebzda, W., Grzesik, B. \& Stępień, M. (2010). Influence of continuous casting conditions on grey cast iron structure. Archives of Materials Science and Engineering. 42(1), 45-52.

[4] Szajnar, J., Stawarz, M., Wróbel, T. \& Sebzda, W. (2010). Laboratory grey cast iron continuous casting line with electromagnetic forced convection support. Archives of Foundry Engineering. 10(3), 171-174.

[5] Lee, D., Kang, S., Cho, D. \& Kim, K. (2006). Effects of casting speed on microstructure and segregation of electromagnetically stirred aluminum alloy in continuous casting process. Rare Metals. 25, 118-123.
[6] Beijiang, Z., Jianzhong, C. \& Guimin, L. (2003). Effects of low-frequency electromagnetic field on microstructures and macrosegregation of continuous casting 7075 aluminum alloy. Materials Science \& Engineering A. A355, 325-330.

[7] Li, Y., Zhang, X., Jia, F., Yao, S. \& Jin, J. (2003). Technical parameters in electromagnetic continuous casting of aluminum alloy. Transactions of Nonferrous Metals Society of China. 13(2), 365-368.

[8] Wróbel, T., Szajnar, J., Bartocha, D. \& Stawarz, M. (2013). The stand of horizontal continuous casting of $\mathrm{Al}$ and its alloys. Archives of Foundry Engineering. 13(3), 113-118.

[9] Yan, Z., Jin, W. \& Li, T. (2012). Effect of rotating magnetic field (RMF) on segregation of solute elements in CuNi10Fe1Mn alloy hollow billet. Journal of Materials Engineering and Performance. 21(9), 1970-1977.

[10] Li, X., Guo, Z., Zhao, X., Wie, B., Chen, F. \& Li, T. (2007). Continuous casting of copper tube billets under rotating electromagnetic field. Materials Science \& Engineering A. 460-461, 648-651.

[11] Szajnar, J. \& Wróbel, T. (2008). Influence of magnetic field and inoculation on size reduction in pure aluminium structure. International Journal of Materials and Product Technology. 33(3), 322-334.

[12] Wróbel, T. (2012). The influence of inoculation type on structure of pure aluminum. In $21^{\text {st }}$ International Conference on Metallurgy and Materials METAL 2012 (pp. 1114-1120). Brno, Czech Republic.

[13] Wróbel ,T. (2013). Transformation of pure Al structure under the influence of electromagnetic field. Advanced Materials Research. 702, 159-164.

[14] Wróbel, T. \& Szajnar, J. (2013). Modification of pure Al and AlSi2 alloy primary structure with use of electromagnetic stirring method. Archives of Metallurgy and Materials. 58(3), 941-944.

[15] Keles, O. \& Dundar, M. (2007). Aluminum foil: its typical quality problems and their causes. Journal of Materials Processing Technology. 186(1-3), 125-137. 